\begin{tabular}{|c|l|}
\hline Title & A seismic slip during the 1996 earthquake swarm in and around the Onikobe geothermal area, NE Japan \\
\hline Author(s) & Takada, Y ouichiro; Furuya, Masato \\
\hline Citation & $\begin{array}{l}\text { Earth and Planetary Science Letters, 290(3-4), 302-310 } \\
\text { https://doi.org/40.1016/.epsl.2009.12.024 }\end{array}$ \\
\hline Issue Date & 2010-02-20 \\
\hline Doc URL & http://hdl.handle.net/2115/42809 \\
\hline Type & article (author version) \\
\hline File Information & EPSL290-3-4_302-310.pdf \\
\hline
\end{tabular}

Instructions for use 


\title{
Aseismic Slip during the 1996 Earthquake Swarm in and around the Onikobe
}

\author{
Geothermal Area, NE Japan
}

\author{
Youichiro Takada* ${ }^{*}$ Masato Furuya ${ }^{1}$ \\ Department of Natural History Sciences, Hokkaido University, N10W8, Kita, \\ Sapporo 060-0810, JAPAN.
}

\begin{abstract}
In August 1996, an earthquake swarm including 4 earthquakes of magnitudes greater than 5 occurred in and around the Onikobe geothermal area, northeast Japan. While earlier studies detected ground displacements by L-band JERS radar interferograms, there remained certain puzzling discrepancies between the observations and the predictions from a seismologically inferred model, and no satisfactory models have yet been proposed. Here, by identifying that a steep gradient in the radar line-ofsight changes exists in seismicity gaps to the east and west of the Torage area (just to the north of the Onikobe caldera), we propose two aseismic reverse faults, which turn out to contribute to a local topographic growth as well as explaining the preexisting discrepancies. Another significant signal is detected in a region in which no large earthquakes occurred; we account for this signal by another aseismic fault. This fault adds to another evidence for the recent hypothesis that aseismic fault motion drives earthquake swarm.
\end{abstract}

Key words: Aseismic Slip, InSAR, Earthquake Swarm, Topographic Growth, Onikobe Caldera 


\section{$1 \quad 1$ Introduction}

2 The Onikobe area in the backbone range running through NE Japan is one 3 of the most active geothermal areas in Japan (Fig. 1) and has been expe4 riencing M5-class earthquakes roughly every 10 years (Umino et al., 1998; 5 Nakajima and Hasegawa, 2003). Four earthquakes of $M \geq 5.0$ occurred in and 6 around the Onikobe caldera on 11 and 13 August 1996; these earthquakes 7 accompanied over 1700 earthquakes of $\mathrm{M}>1$ by the end of September (Japan 8 Meteorological Agency (JMA), Fig. 1), and thus we may regard the entire 9 earthquake sequences as a swarm event. Fig.2 shows the focal mechanisms 10 of major earthquakes determined by Umino et al. (1998), including previous 
dicted from the seismologically derived fault models did not fit the observed InSAR data as we discuss in Section 2.

Here we propose a new fault model that consists of not only seismic but also aseismic faults and discuss its two distinct implications. First, with the aid of a digital elevation model (DEM) and pre-existing geological and aftershock distribution data, we demonstrate that the InSAR data cannot be explained unless we introduce aseismic faults, and that the aseismic slip contributes to local topographic growth. Second, we test an emerging hypothesis that aseismic fault motion drives earthquake swarms, by employing detailed hypocenter data (Vidale and Shearer, 2006; Lohman and McGuire, 2007). Aseismic slip has been documented only in well-developed faults such as oceanic subduction zones (e.g., Heki et al., 1997; Thatcher, 2001), and large scale continental transform faults (e.g., Rosen et al., 1998; Bürgman et al., 2000b; Fielding et al., 2004; Furuya and Satyabala, 2008). Although there are no well-developed faults, the Onikobe area is characterized by very high heat flow and hydrothermal activities, which is preferable for the aseismic slip as demonstrated by some recent studies (McGuire et al., 2005; Vidale and Shearer, 2006; Lohman and McGuire, 2007). Our study verifies that aseismic slips can also occur in undeveloped fault under particular conditions.

\section{Observation Results and Fault Modeling}

InSAR images can detect $\mathrm{mm}$ to $\mathrm{cm}$ order changes in radar line-of-sight (LOS) through differential measurement of the phase component of temporally separated SAR signals (e.g., Massonnet and Feigl, 1998; Bürgmann et al., 2000a; Hanssen, 2001). In this study, we used L-band (wavelength: $23.6 \mathrm{~cm}$ ) JERS 
${ }_{50} \quad \sigma(j)=\sqrt{\frac{\sum_{i=1}^{3}\left(X_{a v r}(j)-X_{i}(j)\right)^{2}}{3-1}}$

${ }_{51}$ where $j$ is the number of pixel, $X_{a v r}(j)$ and $X_{i}(j)$ stand for the phase of 52 the averaged and the $i$-th interferograms, respectively. The denominator is 2

data to overcome interferometric coherence loss because the studied area is densely vegetated. Fig. 3 shows the three interferograms with good coherence created from six independent acquisitions. To suppress atmospheric noise and to evaluate measurement errors, we averaged those three independent interferograms (Fig. 4a) and defined the standard deviation $\sigma$ for each pixel of the averaged interferogram (Fig. 4d) (e.g., Goumelen and Amelung, 2005; Furuya et al., 2007) by the following equation:

considering the unbiasedness. Our aim is to construct a fault model which can explain the averaged interferogram (Fig.4a) within the standard deviation at each pixel (Fig.4d).

Fig. 4a is characterized by the following three distinct signals. First, the largest signal is observed in an inverted triangle-shaped area to the north of the Onikobe caldera, where the radar LOS distance decreases by $14-18 \mathrm{~cm}$ around the Torage (TRG) area (Fig. 1). Particularly remarkable is the very steep gradient in $\triangle$ LOS at the eastern and western margin of this area, which reaches $10 \mathrm{~cm} / \mathrm{km}$ (equivalent to a strain of $10^{-4}$ ) to locally $20 \mathrm{~cm} / \mathrm{km}$ on both sides (Fig. 5 top). Second, a broad positive $\triangle$ LOS up to $5 \mathrm{~cm}$ is observed in the northeastern part of the Onikobe caldera. Finally, a negative $\triangle \mathrm{LOS}$ area is found to the south of the TRG area, where no earthquakes larger than M4.6 took place; this signal is robust in view of the two independent interferograms (Figs. 3b and 3c). It was concluded that all ground deformations occurred 
during the earthquake swarm event because no deformation signal could be detected in the interferograms before and after this event (Fig. 6).

Based on the focal mechanisms of large earthquakes and aftershocks, Umino et al.(1998) proposed a fault model that consists of three faults; we denote Umino et al's three faults as U1, U2, and U3 (Table 1). To represent the four largest earthquakes (Fig. 1), Umino et al. (1998) put U1 for two consecutive M5.9 and M5.4 events on Aug 11, U2 for the M5.7 event on Aug 11, and U3 for the M5.0 event on Aug 13. Fig. 4b shows the calculated $\Delta$ LOS based on Umino et al's model; we used the elastic dislocation model (Okada, 1992) to compute the $\triangle$ LOS. Fig. 4e shows the root mean square (RMS) of the misfit between Figs. 4a and 4b, which can be defined as follows:

$$
R M S(j)=\sqrt{\left(X_{a v r}(j)-X_{s}(j)\right)^{2}}
$$

where $j$ is the number of pixel, $X_{a v r}(j)$ and $X_{s}(j)$ stand for the phase of the averaged and the synthetic interferograms, respectively. Fig. 4e shows large discrepancies to the east and the west of the TRG area, because this fault model cannot explain the steep gradient in $\Delta$ LOS noted above. Even if we considered a heterogeneous slip distribution on U1, we could not explain the steep gradient in $\Delta$ LOS (Supplemental Fig. S1) not only because U1 is too deep (Table 1) to cause such localized signals but also because we assume a plane surface for the slip distribution. $\mathrm{U} 2$ and $\mathrm{U} 3$ are too far to affect the observed steep gradient in $\Delta$ LOS. Also it is unlikely that heterogeneities in elastic properties, if they exist, make such very steep gradient in $\Delta$ LOS. Thus we are led to prescribe two reverse faults at the western and eastern margins of the TRG area, which we hereafter denote F4 and F5. We cannot use seismicity to estimate the geometry of F4 and F5 because few earthquakes occurred 
around these faults (Fig. 1). Instead, when comparing Fig.4a and 4c, the 2dimensional pattern of $\triangle \mathrm{LOS}$ tightly constrains the geometry and location of these faults.

It is unrealistic to constrain all the fault geometries only from seismicities and faults on the surface, as the studied area is highly fractured due to past caldera collapse and each fault is not exposed on the surface as noted above. This is also evidenced by the mismatch between aftershock locations and the geometry of the faults U1-U3. The essence of our modelling strategy is to explain the InSAR data, using minimum number of fault planes. We named each fault of our original model as F1 F2... to clearly distinguish our model from Umino's fault model U1-U3. Considering from different types of focal mechanisms (Fig.2), at the very least, we have to introduce two faults F1 and F2; F1 corresponds to M5.9 and M5.4, and F2 represent M5.7 earthquakes. Meanwhile, comparing Figs. $4 \mathrm{a}$ and $4 \mathrm{~b}$, we cannot find any InSAR signals associated with the M5.0 earthquake that led Umino et al to propose their U3, which is presumably because the moment release is small (Table 1). Therefore, we did not take this earthquake into account. Considering the good accuracy of hypocenter determination, the negative $\triangle \mathrm{LOS}$ to the south of the TRG area is unlikely to be caused by the M5.0 event and therefore it needs to be explained by another source F3, which is not a repositioned model of U3 but totally new fault detected solely by InSAR as well as F4 and F5. It should be noted that this signal is very robust in light of short wavelength and small standard deviation $\sigma$ (Fig.4d). We discuss the geophysical implication of F3 in Section 3.2. Thus, we introduce five faults as the minimum fault number to account for the InSAR and seismological data. We stressed again that few earthquakes occurred in and around the faults F4 and F5, and that there are 
no specific earthquakes correspond to the faults F3-F5 (Figs. 1 and 2).

We first found plausible ranges of each fault parameter by a trial-and-error forward modeling approach, and then adopted a grid-search approach to obtain the fault parameters in our model (Table 2). Although non-linear inversion approach is often taken to constrain nine parameters for a uniform slip model (e.g., Aoki et al.1999), it is unrealistic to precisely determine the 45 independent parameters by any non-linear inversion methods. Also, any non-linear inversion methods need very good initial estimates predetermined by forward modeling. We think that if the initial estimate explains the data (Fig.4a) within the error level (Fig.4d) it should be very close to the true solution, and that our approach is a realistic and reliable way at the moment. Considering the complex crustal structure in this area, we do not rely absolutely on the fault parameters of U1 and U2 in making our model. Actually, we could not explain the InSAR data when we incorporated U1 and U2 in our model without any modifications. We used the fault parameters of U1 and U2 as the initial estimates of F1 and F2. Because of the strong dependence of $\Delta$ LOS on each parameter, the acceptable ranges obtained in our model are quite narrow, especially for the fault location. The synthetic $\Delta \mathrm{LOS}$ calculated from our preferred model and its RMS misfit are shown in Figs. 4c and 4f, respectively. The RMS misfits are largely within the standard deviation of the observed data (Figs. 4d and 4f). However, we can identify a spotty but significant misfit in Fig. 4f. We believe that the spotty misfit is caused by a local small landslide that was probably triggered during the swarm event because (1) the area closely matches the local landslide morphology (H. Yarai and T. Ozawa, personal communication, 2008) and (2) the sign of $\Delta$ LOS is consistent with the direction of the landslide. 
It should be noted that the faults F4 and F5 are located within gaps in the swarm seismicity (Fig. 1), which would be explained by extraordinary high temperature to the east and west of the TRG areas estimated from the bore hole data (Tamanyu et al., 1996), low S-wave velocity anomaly, and anomalously high S-wave attenuation (Onodera et al., 1998). Actually, we also observed few seismicities in the southern part of the Onikobe caldera where geothermal gradients far exceed $200 \mathrm{C}^{\circ} / \mathrm{km}$ and a geothermal power plant exists (PP in Fig.1). The depth of very few earthquakes in the vicinity of F4 and F5 are far deeper than the inferred depth ranges of F4 (0.5 km to $4.5 \mathrm{~km})$ and F5 $(0.6 \mathrm{~km}$ to $6.6 \mathrm{~km})$, and the magnitudes of those earthquakes are very small $(\mathrm{M}<3.0)$. Only one medium earthquake (M4.7) occurred close to the southern tip of F5, but it accounted for only $\sim 20 \%$ of the slip amount of F5. Hence, F4 and F5 clearly represent faults that slipped aseismically, although the exact timing of the slip remains uncertain because of poor time resolution of the InSAR data.

\section{Discussion}

\subsection{Insights Into Topographic Growth}

Cumulative crustal deformation due to repetitive fault motion and surface processes over a long time-scale are known to produce topographic expressions (e.g., Burbank and Anderson, 2001; Hallet and Molnar, 2001). By combining a DEM and the InSAR technique, we have found that the TRG area is an intriguing example of the coupling between tectonics and surface processes.

Fig. 5 (top) shows the cross-sectional profile of the surface topography and 
the $\triangle$ LOS along a track across the TRG area; this figure shows that the location of abrupt changes in $\triangle \mathrm{LOS}$ due to F4 and F5 coincides with that of the sharp ridges at the western and eastern margins of the TRG area. While the subsurface reverse fault motion on F4 and F5 does contribute to the growth of the sharp ridge, the surface processes, especially river incision, also affect topographic evolution because of the high annual rainfall in this region. Within the region bounded by the sharp ridge (indicated by a black line), there are two rivers running in deep V-shaped valleys (Fig. 5 top and middle), which should have denudated the inner flank of the sharp ridge. The combination of the steep and localized deformations due to the slips on F4 and F5 and the river incision process has driven the topographic evolution of the sharp ridge. We also observe a domal topographic high above the central part of F1, where the ground displacement toward satellite culminates (Fig. 5 top and Fig. 4c). River drainage patterns are widely used as good geomorphic markers of crustal deformation (e.g., Burbank and Anderson, 2001; Hallet and Molnar, 2001); Fig. 5 (middle) clearly shows that the two rivers (red lines) change their course around the domal topographic high, which suggests that the domal high grows rapidly at a rate comparable to or faster than the river incision rate. Our model explains this uplift pattern well in terms of the superposition of surface uplift due to F1, F4, and F5. The contributions of F4 and F5 are large because the domal high is located on the hanging-wall side of both faults.

The very steep faults, F4 and F5, would have originated in the Mio-Pliocene caldera collapse, as revealed by detailed geological surveys (Ito et al., 1989; Yoshida, 2001). Although most surface topographies related to the caldera formation are now buried underneath subsequent volcanic sediments, many 
subsurface structures have remained and currently serve as pre-existing weaknesses under the present regional tectonic regime. Umino et al. (1998) have already pointed out the importance of old subsurface caldera structures as pre-existing weaknesses for earthquake rupture; however, this study demonstrates that the old subsurface caldera structures can also generate aseismic slip, such as those found on F4 and F5, and contribute to the topographic growth.

\subsection{Aseismic Fault Drives Earthquake Swarm?}

The stress triggering mechanism has been successfully exploited to account for the spatiotemporal evolution of earthquake sequences (e.g., Stein, 1999; Scholz, 2002). For earthquake swarm episodes around volcanic or geothermal areas, however, Vidale and Shearer (2006) and Vidale et al. (2006) have suggested that pore fluid pressure fluctuation and/or aseismic deformation would be more likely drivers rather than the stress triggering mechanism. Lohman and McGuire (2007) proposed an aseismic fault model to account for the InSAR data associated with the Obsidian Buttes swarm in 2005; their model supports the hypothesis that aseismic creep drives some earthquake swarms.

Among the proposed fault sources, F3, F4, and F5 do not accompany large earthquakes with equivalent moment magnitudes of these faults (Table 2) and thus we conclude that these faults slip primarily aseismically. While F4 and F5 reside in seismicity gaps, we observed numerous small $(\mathrm{M}<4.6)$ earthquakes around F3 (Fig. 1). In contrast to the aftershocks around the fault F1, we confirmed that those earthquakes around F3 did not indicate mainshock-aftershock sequences (Fig. 7a). Despite the small magnitudes of the 
earthquakes, significant deformation was detected by InSAR (Figs. 3 and 4a), and the moment magnitude of F3 far exceeds that of the nearby earthquakes. These observations thus support the emerging model that shallow aseismic slip drives seismic swarms.

Although the studied area lies close to an active volcano, Mt. Kurikoma (Fig. 1), there is no evidence of magma intrusion during the 1996 Onikobe event, unlike other reports, for example, on the eastern Izu-peninsula (Aoki et al., 1999) and near Lake Tahoe (Smith et al., 2004). As another swarm mechanism, pore pressure perturbation cannot be precluded because it can be caused by water as well. The seismic tomography indeed indicates abundant water in the uppermost crust of the Onikobe area (Nakajima and Hasegawa, 2003). It should be noted, however, that such a water-rich environment is also favorable for aseismic slip. In addition, as evidenced by low $V_{s}$ anomaly over $10 \%$ (Onodera et al., 1998) and a very high geothermal gradient (100-150 $\mathrm{C}^{\circ} / \mathrm{km}$, or higher) (Tanaka et al., 1999;Tamanyu et al., 1996), the Onikobe area is clearly under high temperature, which suggests that the brittle-ductile transition zone is shallow and that the aseismic slip on F3 is likely to occur across the transition zone. Considering that there is no direct observation of anomalous water diffusion during the swarm, we speculate that abundant geothermal fluid does not directly drive swarm events but assists aseismic slip. We need to check if aseismic deformation always occurs for the other swarm events as well.

To quantify the amount of aseismic slip on F3, we plotted the depth ranges of the fault slip and seismicity just below and above the fault F1 (Fig.7b) and F3 (Fig.7c), respectively. The localized and robust signal detected by InSAR near F3 (Fig. 4) requires the fault slip on F3 limited to shallow depth. Figure 7b indicates that the fault slip on F3 is much shallower than that of seismicity 
unlike F1 (Fig.7c), which demonstrated that almost all the fault slip on F3 is aseismic. Considering observation errors of the moment magnitudes and hypocentral depths, the aseismic slip on F3 is not obvious. However, such a very shallow earthquake that accounts for the remarkable InSAR signal around F3 is unlikely to occur because of low crustal strength. Thus we conclude that the aseismic slip on F3 is highly likely. Further discussion is difficult because the rock type distribution is very complex and F3 locates in the marginal area of very high geothermal gradient in the southern part of the Onikobe caldera as evidenced by the geothermal power plant, geysers, and few seismicities (Fig.1).

\section{Acknowledgments}

The original JERS-1 SAR data are the copyright of METI/JAXA, Japan. The hypocenter data have been provided by JMA. This work was supported by a Grant-in-Aid for Scientific Research (B), 19340123. We thank Takeyoshi Yoshida, Kosuke Heki and Yukitoshi Fukahata for their helpful comments and discussions. We also thank C.P. Jaupart and two anonymous reviewers for valuable comments.

\section{References}

[1] Aki, K., Richards, P.G., 1980. Quantitative seismology. Freeman, San Francisco.

[2] Aoki, S., Furuya, M., Kobayashi, S., Okubo, S., 2002. Co-seismic crustal deformation of the 1996 Onikobe earthquakes, Japan, detected by InSAR. EOS Trans. AGU. 83, (47), Fall Meet. Suppl. F362.

[3] Aoki, Y., Segall, P., Kato, T., Cervelli, P., Shimada. S., 1999. Imaging magma 
transport during the 1997 seismic swarm off the Izu peninsula, Japan. Science 286, 927-930.

[4] Burbank, D.W., Anderson, R.S., 2001. Tectonic geomorphology. Blackwell Science, Oxford, UK.

[5] Bürgmann, R., Rosen P.A., Fielding, E.J., 2000a. Synthetic aperture radar interferometry to measure Earth's surface topography and its deformation. Annu. Rev. Earth Planet Sci. 28, 169-209.

[6] Bürgmann, R., Schumidt D., Nadeau, R.M., d'Alessio, M., Fielding, E., Manaker, D., McEvilly, T.V., Murray, M.H., 2000b. Earthquake potential along the Northern Hayward Fault, California. Science 289, 1178-1182.

[7] Fielding, E. J., Wright, T.J., Muller, J., Parsons, B.E., 2004. Aseismic deformation of a fold-and-thrust belt imaged by synthetic aperture radar interferometry near Shahdad, southeast Iran. Geology 32, 577-580, doi: 10.1130/G20452.1.

[8] Furuya, M., Mueller, K., Wahr J., 2007. Active salt tectonics in the Needles District, Canyonlands (Utah) as detected by interferometric synthetic aperture radar and point target analysis: 1992-2002. J. Geophys. Res. 112, B06418, doi: 10.1029/2006JB004302.

[9] Furuya, M., Satyabala, S. P., 2008. Slow earthquake in Afghanistan detected by InSAR, Geophys. Res. Lett., 35, L06309, doi:10.1029/2007GL033049.

[10] Geological Survey of Japan (ed.) (2004) Digital Geological Map of Japan 1:200,000, Tohoku. Digital Geoscience Map G20-3, Geological Survey of Japan, AIST

[11] Gourmelen, N., Amelung, F., 2005. Postseismic mantle relaxation in the central Nevada seismic belt. Science 310, 1473-1476. 
[12] Hallet, B., Molnar, P., 2001. Distorted drainage basins as markers of crustal strain east of the Himalaya. J. Geophys. Res. 106, 13697-13709.

[13] Hanssen, R. F., 2001. Radar interferometry -Data Interpretation and Error Analysis-. Kluwer Academic Publishers, Dordrecht, Netherlands.

[14] Heki, K., Miyazaki, S., Tsuji, H., 1997. Silent fault slip following an interplate thrust earthquake at the Japan Trench. Nature 386, 595-598.

[15] Ito, T., Utada M., Okuyama, T., 1989. Mio-Pliocene calderas in the backbone region in northeast Japan (in Japanese with English abstract). Mem. Geol. Soc. Japan 32, 409-429.

[16] Kanamori, H., 1977. The energy release in great earthquakes. J. Geophys. Res. $82,2981-2987$.

[17] Lohman, R.B., McGuire, J.J., 2007. Earthquake swarms driven by aseismic creep in the Salton Trough, California. J. Geophys. Res. 112, B04405, doi: 10.1029/2006JB004596.

[18] Massonnet, D., Feigl, K.L., 1998. Radar interferometry and its application to changes in the Earth's surface. Rev. Geophys. 36, 441-500.

[19] McGuire, J.J., Boettcher, M.S., Jordan, T.H., 2005. Foreshock sequences and short-term earthquake predictability on east pacific rise transform faults. Nature. 434, 457-461.

[20] Nakajima, J., Hasegawa, A., 2003. Tomographic imaging of seismic velocity structure in and around the Onikobe volcanic area, northeastern Japan: Implications for fluid distribution. J. Volcanol. Geotherm. Res. 127, 1-18.

[21] Okada, Y., 1992. Internal deformation due to the shear and tensile faults in a half-space. Bull. Seismo. Soc. America 82, 1018-1042. 
[22] Okada, T., Umino, N., Ito, Y., Matsuzawa, T., Hori, S., Kono, T., Nida, K. Hasegawa, A., 2001. Source process of moderate earthquakes that occurred in the upper crust of NE Japan (in Japanese with English abstract). Bull. Earthq. Res. Inst. Univ. Tokyo 76, 61-74.

[23] Onodera, M., Horiuchi, S., Hasegawa, A., 1998. Three-dimensional seismic velocity structure in and around the focal area of the 1996 Onikobe earthquake based on $V_{p} / V_{s}$ inversion (in Japanese with English abstract). J. Seismol. Soc. Jpn. 51, 265-279.

[24] Rosen, P., Werner, C., Fielding, E., Hensley, S., Buckley, S., Vincent, P., 1998. Aseismic creep along the San Andreas Fault northwest of Parkfield, CA measured by radar interferometry. Geophys. Res. Lett. 25, 825-828.

[25] Scholz, C. H., 2002. The Mechanics of Earthquakes and Faulting. Cambridge University Press, New York.

[26] Smith, K. D., von Seggern, D., Blewitt, G., Preston, L., Anderson, J.G., Wernicke, B.P., Davis, J.L., 2004. Evidence for deep magma injection beneath Lake Tahoe, Nevada-California. Science 305, 1277-1280.

[27] Stein, R. S., 1999. The role of stress transfer in earthquake occurrence. Nature 402, 605-609.

[28] Tamanyu, S., Nomura, K., Yoshizawa, M., 1996. Deep subsurface temperature distribution patterns estimated from temperature logging data: Examples of 14 major geothermal field in Japan (in Japanese with English abstract). Bull. Geol. Surv. Japan 47, (10), 485-548.

[29] Tanaka, A., Yano, Y., Sasada, M., Okubo, Y., Umeda, K., Nakatsuka, N., Akita, F., 1999. Compilation of thermal gradient data in Japan on the basis of the temperatures in boreholes (in Japanese with English abstract). Bull. Geol. Surv. Japan 50, (7), 457-487. 
[30] Thatcher, W., 2001. Silent slip on the Cascadia subduction interface. Science $292,1495-1496$.

[31] Umino, N., Matsuzawa, T., Hori, S., Nakamura, A., Yamamoto, A., Hasegawa, A., Yoshida, T., 1998. 1996 Onikobe earthquakes and their relation to crustal structure (in Japanese with English abstract). J. Seismol. Soc. Jpn. 51, 253-264.

[32] Vidale, J.E., Shearer, P.M., 2006. A survey of 71 earthquake bursts across southern California: Exploring the role of pore fluid pressure fluctuations and aseismic slip as drivers. J. Geophys. Res. 111, B05312, doi: 10.1029/2005JB004034.

[33] Vidale, J.E., Boyle, K.L., Shearer, P.M., 2006. Crustal earthquake bursts in California and Japan: Their patterns and relation to volcanoes. Geophys. Res. Lett. 33, L20313, doi: 10.1029/2006GL027723.

[34] Yarai, H., Murakami, M., Tobita, M., Nakagawa, H., Fujiwara, S., 2002. Crustal deformation associated with earthquakes occurred in north Akita prefecture on August 11, 1996: from JERS-1 SAR interferometry (in Japanese). Programme and abstracts. Seismol. Soc. Jpn. 2002 Fall Meeting, P-202.

[35] Yoshida, T., 2001. The evolution of arc magmatism in the NE Honshu arc, Japan. Sci. Rep. Tohoku Univ. 36, 131-149.

\section{Figure Captions}

Fig. 1. Tectonic map of the 1996 Onikobe earthquake swarm area. The circles indicate the hypocenters given by JMA (11 Aug. 1996 - 30 Sept. 1996). The magnitude and depth of the earthquakes are indicated by radius and color, respectively. The major earthquakes are shown by different symbols: M5.9 (star, 11 Aug.), M5.4 (square, 11 Aug.), M5.7 (diamond, 11 Aug.), M5.0 (inverted triangle, 13 Aug.). The red diamonds indicate major hot springs, geysers, 
and fumaroles. The large red diamond denoted by PP indicates a geothermal power plant. TRG: Mt. Torage, KRK: Mt. Kurikoma (active volcano), ARD: Mt. Arao (active volcano, and the center of the Onikobe caldera). The white broken lines show the location of Fig. 5. The rectangles with solid lines indicate the surface projections of the aseismic faults (F4 and F5 in Table 2). The rectangle with white dotted line indicates the surface projection of another aseismic fault (F3 in Table 2).

Fig. 2. Focal mechanisms of major earthquakes superposed on the geologic map (Geological Survey of Japan, 2004). The focal solutions (lower hemisphere projection) are given by Umino et al.(1998). We added two large earthquakes occurred on 1976 and 1985 for reference. Legend of the geologic map is simplified. The white triangles indicate main landmarks. TRG: Mt. Torage, KRK: Mt. Kurikoma, ARD: Mt. Arao. The solid lines indicate known faults and the broken lines denote concealed faults. The red circle indicates Onikobe Caldera (after Yoshida, 2001). Note that both focal mechanisms and geologic map reflect highly complex crustal structure.

Fig. 3. Interferograms acquired from three independent periods. a) $23 \mathrm{Jul}$. 1995 - 5 Oct. 1996, b) 12 Apr. 1996 - 19 Dec. 1997, c) 9 Jul. 1996 - 13 4 Jun. 1998. Data were taken along descending path 64 and rows 235 to 236. To remove the topographic fringes, we used a digital elevation map with a resolution of $50 \mathrm{~m}$ provided by the Geographical Survey Institute, Japan.

Fig. 4. Comparison between observed and synthetic $\Delta$ LOS. Positive (negative) $\Delta$ LOS stands for an increase (decrease) in the LOS distance. a) Observed $\triangle$ LOS. b) and c) are the synthetic $\triangle$ LOS calculated from the fault model of Umino et al. (1998) and this study, respectively. d) Standard deviation of a). 
See text for details. e) Root mean square (RMS) misfit between a) and b). f) RMS misfit between a) and c). The white frames and vectors indicate the fault surface and slip vectors projected onto the surface, respectively.

Fig. 5. Spatial relationship between $\Delta$ LOS, topography, and inferred aseismic faults. The location is indicated in Fig. 1. Top: $\triangle$ LOS (blue) and altitude (red) along the white line in the middle figure. Middle: 3D view of the Torage area from the north. $\triangle$ LOS value is draped onto the topography. The triangle indicates the summit of Mt. Torage $(1432.9 \mathrm{~m})$. The marked negative $\Delta \mathrm{LOS}$ area is surrounded by a sharp ridge (black line). The domal topographic high inside the sharp ridge shows good spatial correlation with the negative $\Delta$ LOS area. The red lines indicate major rivers flowing in deep valleys. Bottom: 3D view of the inferred high dip-angle aseismic faults (F4 and F5) running parallel to the sharp ridge.

Fig. 6. Interferograms obtained before and after the earthquake swarm. (a) 12 Apr. 1996 - 9 Jul. 1996 (before), (b) 5 Oct. 1996 - 19 Dec. 1997 (after), (c) 19 Dec. 1997 - 13 Jun. 1998 (after).

Fig. 7. (a)Time sequence of the earthquakes around F1 and F3 during 1114 August 1996. The red and green crosses correspond to the earthquakes with those epicenters inside the surface projection of F1 and F3, respectively (Figs. 1 and 4c). The magnitudes are normalized by those of the largest earthquake for both sequences. The green symbols do not indicate the mainshockaftershock sequence unlike the red symbols. Depth distribution of earthquakes with those epicenters inside the surface projection of (b) F1 and (c) F3 are also plotted. Red bar in (b) and green bar in (c) indicate the depth range of the fault F1 and F3, respectively. 
${ }_{416}$ Fig. S1. Fault modeling considering slip distribution. (a) Observed $\Delta$ LOS ${ }_{417}$ (Fig.4a). (b) Synthetic $\triangle$ LOS based on distributed slip fault models, Um1 and ${ }_{418} \mathrm{Um} 2$. The location and geometry of Um1 and Um2 are slightly modified from ${ }_{419}$ Umino et al.'s U1 and U2. Slip distribution on Um1 and Um2 are indicated in ${ }_{420}$ (c) and (d), respectively. Color indicates the amount of slip in meter. Bottom ${ }_{421}$ depth, length, width, dip, and strike of Um1 is $7.5 \mathrm{~km}, 10 \mathrm{~km}, 5 \mathrm{~km}, 45$ degree, ${ }_{422}$ and 350 degree, respectively. Those for $U \mathrm{~m} 2$ is $8.0 \mathrm{~km}, 11 \mathrm{~km}, 5 \mathrm{~km}, 90$ degree, ${ }_{423}$ and 225 degree, respectively. 
Table 1. Fault parameters estimated from the seismological data.

\begin{tabular}{lcccccccccc}
\hline Fault & $\begin{array}{c}\text { Longitude }^{\mathrm{a}} \\
(\mathrm{deg})\end{array}$ & $\begin{array}{c}\text { Latitude }^{\mathrm{a}} \\
(\mathrm{deg})\end{array}$ & $\begin{array}{c}\text { Length } \\
(\mathrm{km})\end{array}$ & $\begin{array}{c}\text { Width } \\
(\mathrm{km})\end{array}$ & $\begin{array}{c}\text { Depth }^{\mathrm{a}} \\
(\mathrm{km})\end{array}$ & $\begin{array}{c}\text { Dip }^{\mathrm{b}} \\
(\mathrm{deg})\end{array}$ & $\begin{array}{c}\text { Strike }^{\mathrm{b}} \\
(\mathrm{deg})\end{array}$ & $\begin{array}{c}\text { Rake }^{\mathrm{b}} \\
(\mathrm{deg})\end{array}$ & $\begin{array}{c}\text { Slip } \\
(\mathrm{cm})\end{array}$ & Mw $^{\mathrm{c}}$ \\
\hline $\mathrm{U} 1$ & 140.627 & 38.899 & 10.0 & 8.2 & 7.5 & 45.0 & 350.0 & 90.0 & 60 & 6.15 \\
$\mathrm{U} 2$ & 140.649 & 38.855 & 10.0 & 6.0 & 7.0 & 90.0 & 47.0 & 180.0 & 40 & 5.94 \\
$\mathrm{U} 3$ & 140.576 & 38.800 & 5.0 & 3.0 & 8.0 & 50.0 & 49.0 & 120.0 & 40 & 5.54 \\
\hline
\end{tabular}

Each value was scanned from Figure 9 in Umino et al. (1998). We also referred to Okada et al. (2001) while obtaining some parameters from Umino et al. (1998).

${ }^{\mathrm{a}}$ The position is for the center of each fault plane.

${ }^{\mathrm{b}}$ We adopted the convention defined by Aki and Richards (1980).

${ }^{\mathrm{c}}$ Equivalent moment magnitude defined by Kanamori (1977). 
Table 2. Fault parameters of our model and those acceptable ranges indicated by \pm .

\begin{tabular}{|c|c|c|c|c|c|c|c|c|c|c|}
\hline Fault & $\begin{array}{c}\text { Longitude }^{\mathrm{a}} \\
\text { (deg) }\end{array}$ & $\begin{array}{c}\text { Latitude }^{\mathrm{a}} \\
\text { (deg) }\end{array}$ & $\begin{array}{l}\text { Length } \\
(\mathrm{km})\end{array}$ & $\begin{array}{l}\text { Width } \\
(\mathrm{km})\end{array}$ & $\begin{array}{l}\text { Depth }^{\mathrm{a}} \\
(\mathrm{km})\end{array}$ & $\begin{array}{l}\mathrm{Dip}^{\mathrm{b}} \\
(\mathrm{deg})\end{array}$ & $\begin{array}{l}\text { Strike }^{\mathrm{b}} \\
\text { (deg) }\end{array}$ & $\begin{array}{l}\text { Rake }^{\mathrm{b}} \\
\text { (deg) }\end{array}$ & $\begin{array}{l}\text { Slip } \\
\text { (cm) }\end{array}$ & $\mathrm{Mw}^{\mathrm{c}}$ \\
\hline $\mathrm{F} 1$ & $140.640 \pm 0.003$ & $38.905 \pm 0.003$ & $9.0 \pm 0.5$ & $5.3 \pm 0.3$ & $6.7 \pm 0.3$ & $40.0 \pm 2.5$ & $340.0 \pm 5.0$ & $110 \pm 5$ & $52 \pm 3$ & $5.95 \pm 0.05$ \\
\hline F2 & $140.650 \pm 0.002$ & $38.860 \pm 0.002$ & $7.8 \pm 0.5$ & $6.8 \pm 0.2$ & $5.5 \pm 0.2$ & $80.0 \pm 2.5$ & $47.0 \pm 2.0$ & $-169 \pm 1$ & $44 \pm 3$ & $5.93 \pm 0.04$ \\
\hline F3 & $140.648 \pm 0.002$ & $38.831 \pm 0.003$ & $5.8 \pm 0.4$ & $2.0 \pm 0.2$ & $2.1 \pm 0.3$ & $37.5 \pm 2.5$ & $12.5 \pm 2.5$ & $115 \pm 3$ & $30 \pm 2$ & $5.38 \pm 0.07$ \\
\hline F4 & $140.601 \pm 0.001$ & $38.909 \pm 0.001$ & $6.0 \pm 0.5$ & $4.0 \pm 0.2$ & $2.5 \pm 0.1$ & $86.0 \pm 2.0$ & $325.0 \pm 2.5$ & $80 \pm 10$ & $20 \pm 2$ & $5.48 \pm 0.07$ \\
\hline F5 & $140.663 \pm 0.002$ & $38.916 \pm 0.002$ & $5.0 \pm 0.5$ & $6.0 \pm 0.2$ & $3.6 \pm 0.2$ & $84.0 \pm 2.0$ & $21.0 \pm 5.0$ & $90 \pm 10$ & $20 \pm 5$ & $5.54 \pm 0.11$ \\
\hline
\end{tabular}

${ }^{\mathrm{a}}$ The position is for the center of each fault plane.

${ }^{\mathrm{b}}$ We adopted the convention defined by Aki and Richards (1980).

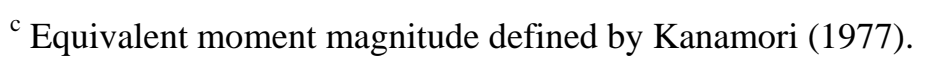




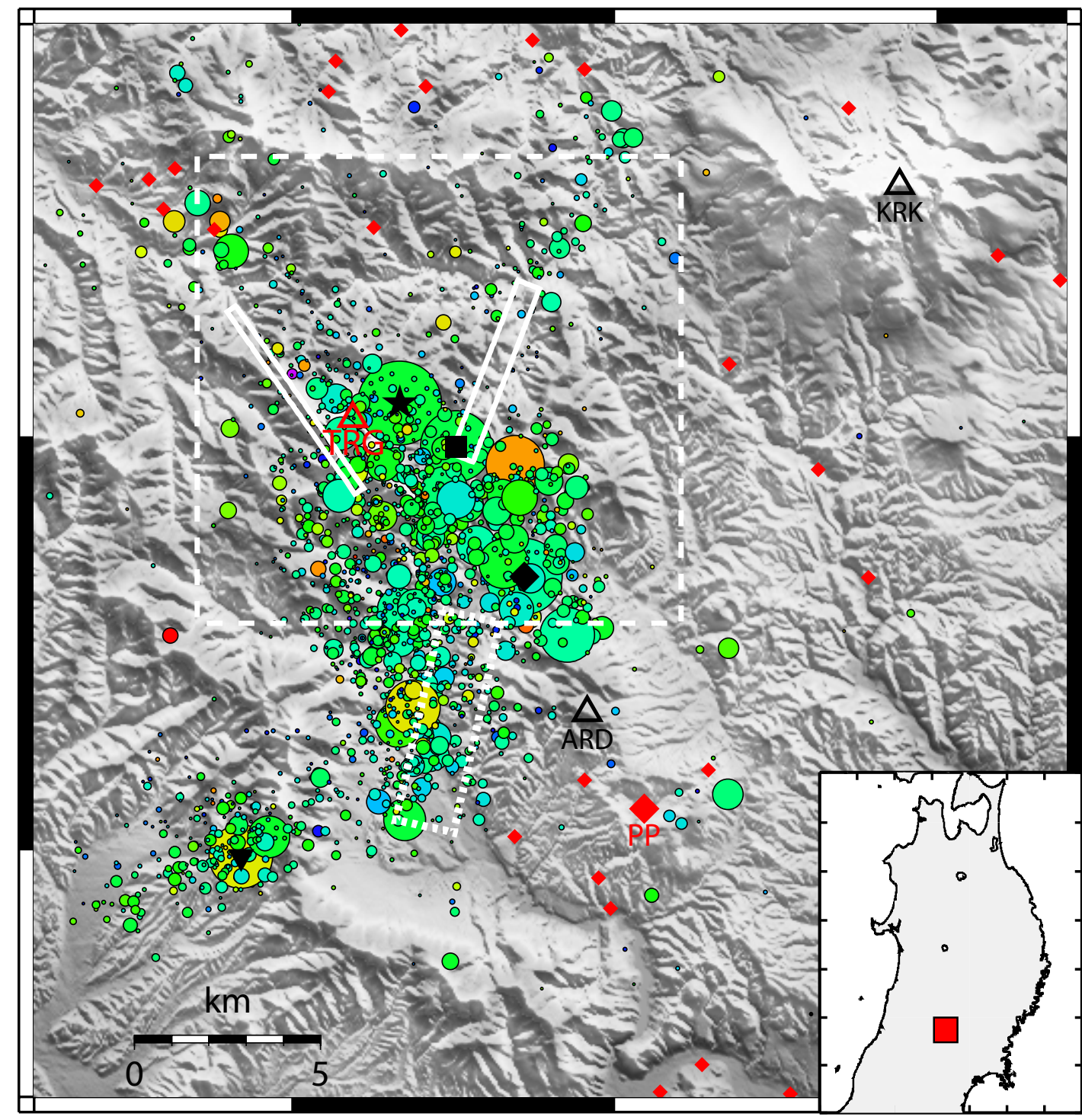

$38^{\circ} 48^{\prime}$

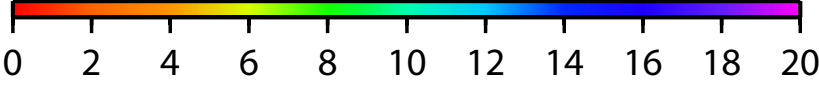
Depth [km]
Magnitude

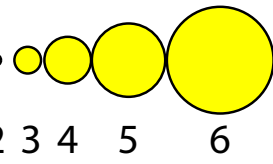

Fig.1 
a) 23 Jul.1995 - 5 Oct. 1996

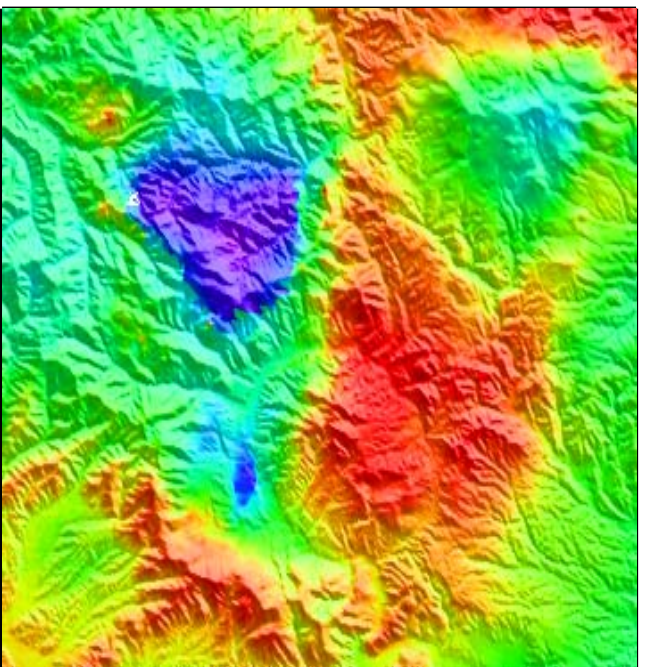

b) 12 Apr.1996 - 19 Dec. 1997



C) 9 Jul.1996 - 13 Jun. 1998



$$
\begin{gathered}
-18-16-14-12-10-8-6-4-2 \quad 0 \quad 2 \quad 4 \quad 6 \\
\Delta \operatorname{LOS}[\mathrm{cm}]
\end{gathered}
$$

Fig.3 
Fig.5
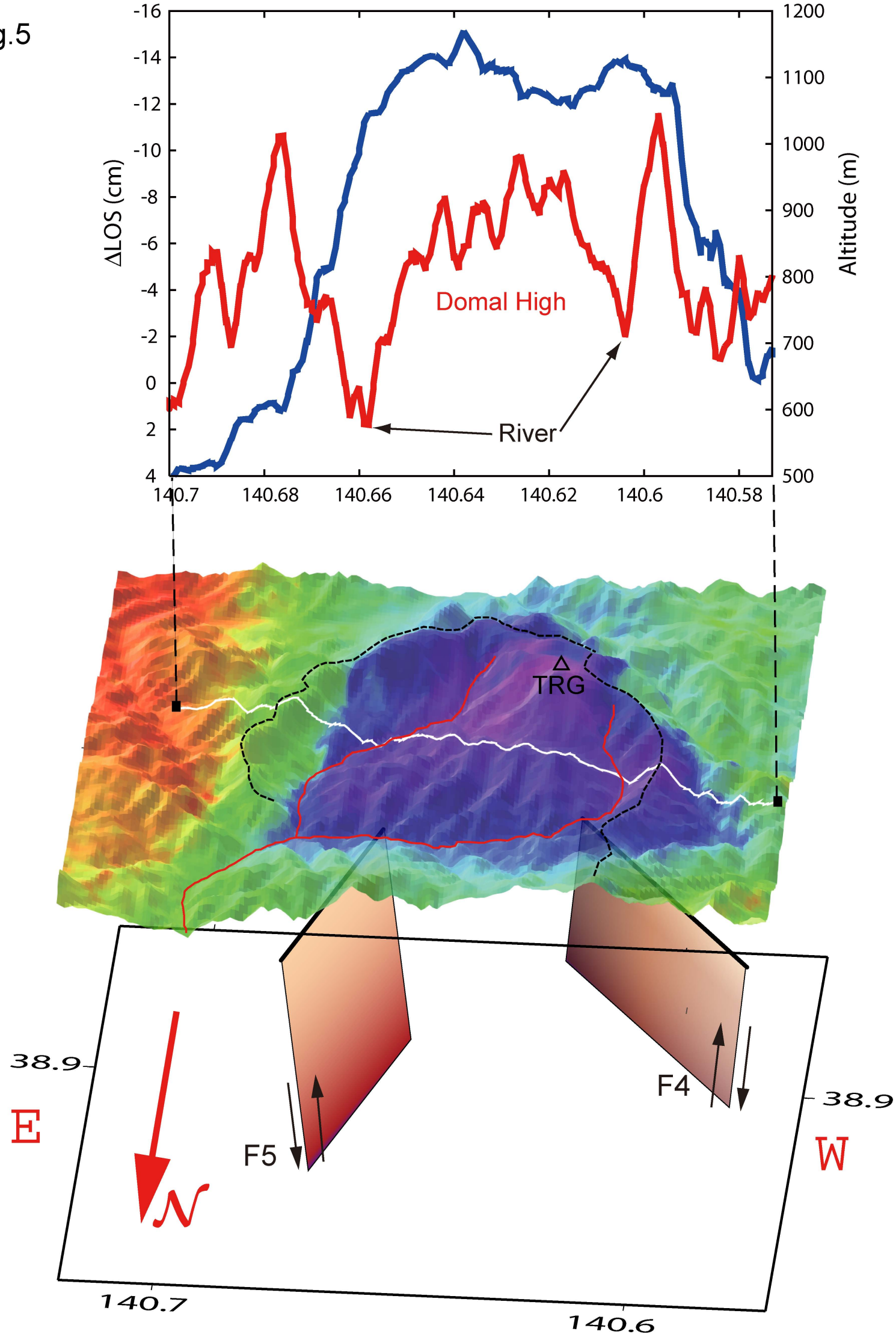
a) 12 Apr. 1996 - 9 Jul. 1996

b) 5 Oct. 1996 - 19 Dec. 1997

C) 19 Dec. 1997 - 13 Jun. 1998

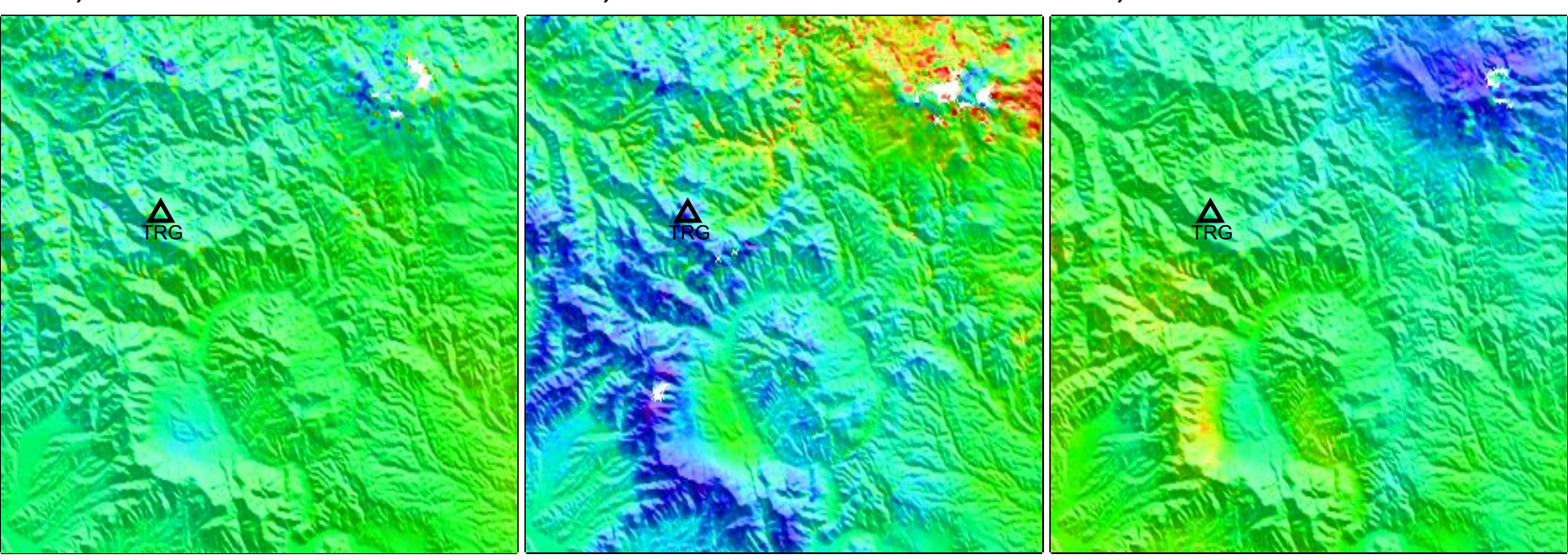

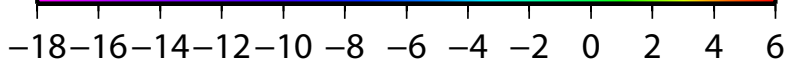

$$
\begin{aligned}
& \Delta \operatorname{LOS}[\mathrm{cm}]
\end{aligned}
$$

Fig.6 
